\title{
HUBUNGAN STRES KERJA DENGAN KINERJA PERAWAT DI RUANG RAWAT INAP MELATI DAN SERUNI RSUD DR. M. YUNUS BENGKULU
}

\author{
Dian Dwiana Maydinar ${ }^{1}$, Fatima Nuraini Sasmita ${ }^{2}$, Venni Selandio ${ }^{3}$ \\ Program Studi S1 Keperawatan, STIKES Tri Mandiri Sakti Bengkulu \\ diandwiananers@gmail.com ${ }^{1,}$ nurainisasmita24@gmail.com²
}

\begin{abstract}
Stress is a response that is not specific, linked by individual characteristics or psychological processes, which is a consequence of any external actions, situations, or events that cause physical or psychological demands on a person. The purpose of this study was to study the relationship of work stress with the performance of nurses in jasmine and seruni inpatients in Dr. M. Yunus Bengkulu. This type of research is analytic observational using a correlational design and using total sampling techniques with inclusion and exclusion criteria in 43 respondents. The population of this study was inpatient nurses in jasmine and seruni rooms. Date collection techniques by interviewing nurses in jasmine and seruni room using a questionnaire guide. Results of the study: From 43 nurses in the Melati and Seruni Inpatient Room Dr. M. Yunus Bengkulu, 21 nurses (48.8\%) experienced mild work stress, 19 people (44.2\%) moderate work stress and 3 other people (7\%) experienced severe work stress, from 43 nurses in the ward Inap Melati and Seruni Hospital Dr. M. Yunus Bengkulu, 20 nurses (46.5\%) good nurse performance, 22 people (51.2\%) enough nurse performance and 1 person (2.3\%) nurse performance is not good and based on Spearman Rank obtained Rho value $=0.377$ with $p$ value $=0.013<0.05$ means significant, thus it can be concluded that there is a relationship between work stress and the performance of nurses in jasmine and seruni inpatients in Dr. M. Yunus Bengkulu.
\end{abstract}

Keywords $\quad$ : Job Stress, Nurse Performance

\section{ABSTRAK}

Stres merupakansuatu respon yang tidak spesifik, dihubungkan oleh karakteristik atau proses psikologi individu, yang merupakan suatu konsekuensi dari setiap tindakan eksternal, situasi, atau peristiwa yang menimbulkan tuntutan fisik atau psikologi pada seseorang. Tujuan penelitian ini adalah untuk mempelajari hubungan stres kerja dengan kinerja perawat diruang rawat inap melati dan seruni di RSUD Dr. M. Yunus Bengkulu. Jenis penelitian ini adalah observasional analitik dengan menggunakan rancangan korelasional dan menggunakan teknik total sampling dengan kriteria inklusi dan eklusipada 43 responden. Populasi penelitian ini adalah perawat rawat inap di ruang melati dan seruni. Teknik pengumpulan data dengan wawancara pada perawat ruang melati dan seruni menggunakan panduan kuesioner. Hasil penelitian: Dari 43 perawat di Ruang Rawat Inap Melati dan Seruni RSUD Dr. M. Yunus Bengkulu, 21 orang perawat $(48,8 \%)$ mengalami stres kerja ringan, 19 orang $(44,2 \%)$ stres kerja sedang dan 3 orang lainnya (7\%) mengalami stres kerja berat, Dari 43 orang perawat di Ruang Rawat Inap Melati dan Seruni RSUD Dr. M. Yunus Bengkulu, 20 orang perawat $(46,5 \%)$ kinerja perawat baik, 22 orang $(51,2 \%)$ kinerja perawat cukup dan 1 orang $(2,3 \%)$ kinerja perawat kurang baik dan berdasarkan Rank Spearman didapat nilai Rho $=0,377$ dengan $\mathrm{p}$ value $=0,013<0,05$ berarti signifikan, dengan demikian dapat disimpulkan bahwa Ada hubungan antara stres kerja dengan kinerja perawat diruang rawat inap melati dan seruni RSUD Dr. M. Yunus Bengkulu

Kata Kunci : Stress Kerja, Kinerja Perawat 


\section{PENDAHULUAN}

Profesi perawat mempunyai resiko yang sangat tinggi terkena stres, karena perawat memiliki tugas dan tanggung jawab yang sangat tinggi terhadap keselamatan manusia. Masalah-masalah yang sering dihadapi perawat diantaranya: meningkatnya stres kerja karena dipacu harus selalu maksimal dalam melayani pasien. Orang yang terkena stres kerja (dengan catatan, tidak dapat menanggulanginya) cenderung tidak produktif, secara tidak sadar malahmenunjukan kebodohannya, malasmalasan, tidak efektif dan efisien dan berbagai sikap yang dapat merugikan organisasi. (Rahman dkk, 2017)

World Health Organization (WHO) menyatakan stres merupakan epidemi yang menyebar ke seluruh dunia. The American Institute of Stress menyatakan bahwa penyakit-penyakit yang berhubungan dengan stres telah menyebabkan kerugian ekonomi Amerika serikat lebih dari \$100 miliar pertahun. Survey atas pekerja tenaga perawat pelaksana di Amerika Serikat menemukan bahwa $46 \%$ merasakan pekerjaan mereka penuh dengan stres dan $34 \%$ berfikir serius untuk keluar dari pekerjaan mereka 12 bulan sebelumnya karena stres ditempat kerja. (Fajrillah \& Nurfitriani, 2016)

Stres kerja perawat di Indonesia dibagi menjadi dua kategori dengan persentase stres sedang $65 \%$ dan kurang baik $70 \%$ (Ahsan, Suprianti, \& Elnita, 2013).

Hasil penelitian yang dilakukan oleh Sani (2014) menyebutkan bahwa 50,9\% perawat Indonesia yang mengalami stres kerja, sering merasa pusing, lelah, kurang ramah, kurang istirahat akibat beban kerja terlalu tinggi serta penghasilan yang tidak memadai.

Perawat sebagai salah satu tenaga kesehatan di rumah sakit memegang peranan penting dalam upaya mencapai tujuan pembangunan kesehatan. Keberhasilan pelayanan kesehatan bergantung pada partisipasi perawat dalam memberikan asuhan keperawatan yang berkualitas bagi pasien.

Hal ini terkait dengan keberadaan perawat yang bertugas selama 24 jam melayani pasien, serta jumlah perawat yang mendominasi tenaga kesehatan di rumah sakit, yaitu berkisar 40-60\%. Oleh karena itu, rumah sakit haruslah memiliki perawat yang berkinerja baik yang akan menunjang kinerja rumah sakit sehingga dapat tercapai kepuasan pelanggan atau pasien (Swansburg, 2000 dalam Suroso, 2011).

Stres adalah suatu respon yang tidak spesifik, dihubungkan oleh karakteristik atau proses psikologi individu, yang merupakan suatu konsekuensi dari setiap tindakan eksternal, situasi, atau peristiwa yang menimbulkan tuntutan fisik atau psikologi pada seseorang (Kreitner \& Kinichi 2005). Menurut Handoko (2001) stres adalah suatu kondisi ketegangan yang mempengaruhi emosi, proses berfikir dan kondisi seseorang. Jika stres yang dialami melibatkan juga pihak organisasi atau perusahaan tempat individu bekerja seseorang dapat dikategorikan mengalami stres kerja

Kinerja menunjukkan akuntabilitas lembaga pelayanan dalam rangka tata pemerintah yang baik. Menurut Handoko (2001) kinerja adalah prestasi kerja, yaitu proses yang dilalui dalam organisasi untuk mengevaluasi atau menilai prestasi kerja karyawan. Pelaksanaan kerja perawat sebagai profesi yang mengemban tanggung jawab yang besar dan menuntun kepada anggotanya untuk memiliki sikap, pengetahuan dan keterampilan diterapkan pada asuhan keperawatan sesuai dengan standar dan kode etik profesi (Subanegara, 2005)

Menurut Gibson, dkk (1997) dalam Nasution tahun (2009), masa kerja seseorang akan menentukan prestasi individu yang merupakan dasar prestasi dan kinerja organisasi.

Semakin lama seseorang bekerja di suatu organisasi, maka tingkat prestasi individu akan semakin meningkat yang dibuktikan dengan tingginya tingkat 
penjualan dan akan berdampak kepada kinerja dan keuntungan organisasi yang menjadi lebih baik, sehingga memungkinkan untuk mendapatkan promosi atau kenaikan jabatan.

Penelitian yang dilakukan oleh Adri Dwi Putra Sani pada tahun 2014 dengan judul "Hubungan Stres Kerja Dengan Kinerja Perawat di Instlasi Rawat Inap Ruang Melati (C2) RSUD DR.M.YUNUS Bengkulu" terdapat 30 perawat dapat diketahui sebagian besar mengalami stres kerja tinggi yaitu 16 perawat $(53,3 \%)$, dari 30 perawat dapat diketahui sebagian besar kinerja perawat kurang baik yaitu 12 perawat $(40,0 \%)$ dan dapat disimpulkan terdapat hubungan yang signifikan antara stres kerja dengan kinerja perawat di Instlasi rawat inap ruang Melati (C2) RSUD DR. M. Yunus Bengkulu dengan kategori erat.

Berdasarkan hasil survey yang dilakukan peneliti di ruang rawat inap melati dan seruni di RSUD Dr. M. Yunus di dapatkan jumlah perawat dimasingmasing ruangan ditotalkan berjumlah 43 orang perawat dengan perawat DIII berjumlah 12 orang, S1 24 orang, dan Ners 7 orang dengan lama bekerja, pada ruangan melati 3 orang $>20$ tahun, 9 orang bekerja selama 12 tahun, 2 orang bekerja selama 10 tahun, 8 orang bekerja dibawah 5 tahun dan di ruangan seruni 1 orang bekerja selama 26 tahun, 2 orang bekerja selama 12 tahun, 2 orang bekerja selama 10 tahun, dan 16 orang bekerja kurang lebih 6-8 tahun.

RSUD Dr. M. Yunus Bengkulu merupakan Rumah Sakit Umum rujukan tertinggi di provinsi Bengkulu yang mempunyai andil dan peranan dalam meningkatkan kesehatan masyarakat provinsi Bengkulu, guna untuk membantu penyembuhan para penderita penyakit yang datang berobat ke rumah sakit. Upaya tersebut meliputi promotif, prefentif, kuratif dan rehabilitatif (Profil RSUD. DR. M. Yunus, 2011). Adapun unit perawatan rawat inap yang ada di RSUD Dr. $M$. Yunus Bengkulu terdiri dari beberapa ruang perawatan, salah satunya ruang rawat inap melati dan seruni.

Berdasarkan latar belakang rumusan masalah dalam penelitian ini adalah "Ada hubungan antara stres kerja dengan kinerja perawat diruang rawat inap melati dan serui RSUD Dr. M. Yunus Bengkulu, diharapkan pihak RSUD Dr. M.Yunus Bengkulu. Tujuan dari penelitian ini adalah untuk mempelajari Ada hubungan antara stres kerja dengan kinerja perawat diruang rawat inap Melati dan Seruni RSUD Dr. M. Yunus Bengkulu, diharapkan pihak RSUD Dr. M.Yunus Bengkulu.

\section{METODE}

Penelitian dilakukan di ruang Melati dan Seruni RSUD DR. M. Yunus Kota Bengkulu. Jenis penelitian ini adalah observasional analitik dengan menggunakan rancangan korelasional dan menggunakan teknik Total Sampling pada 43 responden. Populasi penelitian ini adalah perawat di ruang melati dan seruni RSUD DR. M. Yunus Bengkulu. Teknik pengumpulan data dilakukan dengan menggunakan data primer. Teknik analisis data dilakukan dengan analisis univariat dan bivariat dengan uji korelasi Rank Spearman.

\section{HASIL}

Analisis univariat bertujuan untuk mengetahui gambaran stress kerja dengan kinerja perawat di ruang melati dan seruni RSUD DR. M. Yunus Bengkulu 
Tabel 1. Distribusi frekuensi stress kerja perawat di Ruang Rawat Inap Melati dan Seruni RSUD Dr. M. Yunus Bengkulu

\begin{tabular}{llcc}
\hline No & Stress Kerja & Frekuensi & Persentase (\%) \\
1. & Ringan & 21 & 48,8 \\
2. & Sedang & 19 & 44,2 \\
3. & Berat & 3 & 7,0 \\
\hline & Total & 43 & 100,0 \\
\hline
\end{tabular}

Berdasarkan tabel 1,diketahui dari 43 perawat di Ruang Rawat Inap Melati dan Seruni RSUD Dr. M. Yunus Bengkulu, 21 orang perawat $(48,8 \%)$ mengalami stres kerja ringan, 19 orang $(44,2 \%)$ stres kerja sedang dan 3 orang perawat $(7 \%)$ mengalami stres kerja berat dan diantara stres kerja perawat di ruang rawat inap melati dan seruni tingkat stres paling tinggi yaitu stres kerja ringan sebanyak 21 perawat $(48,8 \%)$.

Tabel 2 Distribusi frekuensi kinerja perawat di Ruang Rawat Inap Melati dan Seruni RSUD Dr. M. Yunus Bengkulu

\begin{tabular}{llcc}
\hline No & Kinerja perawat & Frekuensi & Persentase $(\%)$ \\
1 & Baik & 20 & 46,5 \\
2 & Cukup & 22 & 51,2 \\
3 & Kurang Baik & 1 & 2,3 \\
\hline \multicolumn{2}{c}{ Total } & 43 & 100,0 \\
\hline
\end{tabular}

Berdasarkan tabel 2 diketahui dari 43 perawat kurang baik, dari data diatas orang perawat di Ruang Rawat Inap Melati didapatkan bahwa kinerja perawat di Ruang dan Seruni RSUD Dr. M. Yunus Bengkulu, Rawat Inap Melati dan Seruni di RSUD Dr. 20 orang perawat $(46,5 \%)$ kinerja perawat M. Yunus Bengkulu terdapat kinerja perawat baik, 22 orang $(51,2 \%)$ dengan kinerja terbanyak 22 orang dengan kinerja cukup. perawat cukup dan 1 orang $(2,3 \%)$ kinerja

Tabel 3 Uji Normalitas Data stress kerja dan kinerja perawat di Ruang Rawat Inap Melati dan Seruni RSUD Dr. M. Yunus Bengkulu

\begin{tabular}{ccccccc}
\hline \multirow{2}{*}{ Variabel } & \multicolumn{3}{c}{ Tests of Normality } & \multicolumn{3}{c}{ Shapiro-Wilk } \\
& Kolmogorov-Smirnov & & \\
& Statistic & Df & Sig. & Statistic & df & Sig. \\
\hline Stres Kerja & .180 & 43 & .001 & .906 & 43 & .002 \\
Kinerja Perawat & .220 & 43 & .000 & .910 & 43 & .003
\end{tabular}

Berdasarkan tabel 3 hasil uji normalitas data diketahui hasil/nilai: Pvalue $=0,002<0,05$ untuk data stres kerja, berarti data tidak normal, Pvalue $=0,003<0,05$ untuk data kinerja perawat, berarti data tidak normal. Karena kedua data tidak normal, maka tidak memenuhi syarat untuk dilakukan analisis korelasi Product Moment Pearson. Selanjutnya akan dianalisis dengan korelasi Rank Spearman (rho).

\section{Analisis Bivariat}

Analisis ini dilakukan untuk mengetahui keeratan hubungannya digunakan uji statistik korelasi rank spearman. 
Tabel 4 Uji Korelasi Rank Spearman stres kerja dan kinerja perawat di Ruang Rawat Inap Melati dan Seruni RSUD Dr. M. Yunus Bengkulu

\begin{tabular}{ccccccc}
\hline Stres Kerja & \multicolumn{3}{c}{ Kinerja Perawat } & Total & Rho & P \\
\cline { 2 - 4 } & Baik & Cukup & $\begin{array}{c}\text { Kurang } \\
\text { Baik }\end{array}$ & & & \\
\hline Ringan & 4 & 17 & 0 & 21 & & \\
Sedang & 15 & 3 & 1 & 19 & 0,377 & 0,013 \\
Berat & 1 & 2 & 0 & 3 & & \\
\hline Total & 20 & 22 & 43 & 43 & & \\
\hline
\end{tabular}

Berdasarkan tabel 4 uji korelasi Rank spearman stres kerja dengan kinerja perawat di atas, didapatkan bahwa terdapat 21 orang stres kerja ringan dengan 4 orang dengan kinerja baik dan 17 orang dengan kinerja cukup, dari 19 orang stres kerja sedang terdapat 15 orang dengan kinerja baik, 3 orang orang dengan kinerja cukup, dan 1 orang dengan kinerja kurang baik, dari 3 orang stres kerja berat terdapat 1 orang dengan kinerja baik dan 2 orang dengan kinerja cukup.

Hasil korelasi Rank Spearman didapat nilai $\mathrm{Rho}=0,377$ dengan $\mathrm{p}$ value $=0,013<0,05$ berarti signifikan, maka Ho ditolak dan Ha diterima. Jadi Ada hubungan antara stres kerja dengan kinerja perawat di ruang rawat inap melati dan serui RSUD Dr. M. Yunus Bengkulu. Karena nilai rho $=0,377$ terletak dalam interval $0,20-0,40$ maka kategori hubungan adalah lemah, sedangkan 1- 0 , $377=0,623$ disebabkan oleh faktor lain.

\section{PEMBAHASAN}

Analisis menggunakan uji Rank Spearman menunjukkan ada hubungan stress kerja dengan kinerja perawat di ruang Melati dan Seruni di RSUD DR. M. Yunus Bengkulu.

Menurut Haryuni (2013), mengatakan stres kerja sebagai sebuah respon terhadap hilangnya kendali terhadap kinerja kita. Menurut Ivancevich dan Matteson, dikutip Luthans (2011), mengatakan bahwa stres kerja didefinisikan sebagai sebuah respon adaptif (tanggapan penyesuaian) dimediasi oleh perbedaan individu dan atau proses psikologi, sebagai akibat dari aksi lingkungan, situasi atau peristiwa yang menyebabkan tuntutan fisik dan atau psikologi secara berlebihan terhadap seseorang. Sedangkan Beehr dan Newman seperti dikutip oleh Luthans (2011) mengartikan stres kerja sebagai sebuah kondisi yang terjadi sebagai hasil interaksi antara pegawai dengan pekerjaan mereka dan dikarakteristikan atau ditandai oleh perubahan manusia yang memaksa mereka untuk menyimpang dari fungsi normal mereka.

Hasil uji analisis korelasi Rank Spearmans $\mathrm{Rho}=0,377$ dengan $\mathrm{p}$ value $=0,013<0,05$ berarti signifikan, maka Ho ditolak dan Ha diterima. Jadi Ada hubungan antara stres kerja dengan kinerja perawat diruang rawat inap melati dan serui RSUD D.r. M. Yunus Bengkulu. Hal ini menunjukkan bahwa nilai rho $=0,377$ terletak dalam interval 0,20 0,40 maka kategori hubungan adalah lemah, sedangkan 1- $0, \quad 377=0,623$ disebabkan oleh faktor lain.

Hasil penelitian sejalan dengan penelitian terdahulu menurut Perwitasari (2016) penelitian ini sejalan dengan penelitian Wollah, Rompas, dan Kallo (2017), hasil penelitian menunjukkan ada hubungan signifikan antara stres kerja dengan kinerja pada perawat di instalasi gawat darurat dan intensive care unit RSU pancaran kasih GMIM Manado, sejalan dengan penelitian Fajrilah dan Nurfiriani, hasil peneitian menunjukkan adanya hubungan yang signifikan antara stress kerja dan kinerja perawat pelaksana dalam melaksanakan pelayanan kesehatan, saran untuk tenaga perawat agar lebih mengantisipasi atau menyelesaikan stres yang dialami dengan mekanisme koping yang adaptif sehingga tidak berpengaruh negative pada pelayanan keperawatan 
yang sesuai dengan standar asuhan keperawatan professional.

Hasil penelitian menunjukan terdapat hubungan yang signifikan antara stres kerja dengan kinerja perawat dalam kategori lemah Karena nilai rho $=0,377$ terletak dalam interval $0,20-0,40$ maka kategori hubungan adalah lemah, sedangkan $1-0,377=0,623$ disebabkan oleh faktor lain.

Menurut Triwibowo (2013) menyatakan bahwa kinerja karyawan merupakantujuan akhir dan merupakan cara bagi manajer untuk memastikan bahwa aktivitas karyawan dan output yang dihasilkan kongruen dengan tujuan organisasi.

Perawat sebagai salah satu tenaga kesehatan di rumah sakit yang memegang peranan penting dalam upaya pembangunan kesehatan dan perawat memiliki tugas dan tanggung jawab yang sangat tinggi terhadap keselamatan manusia. Perawat yang mengalami stres kerja ringan dapat mengasilkan kinerja yang baik maka sebaliknya apabila perawat mengalami stres kerja berat maka akan berdampak pula teradap kinerjanya dan dapat mengurangi kualitas dari rumah, maka dari itu diharapkan kepada tenaga kesehatan khususnya perawat yang berada di ruangan melati dan seruni untuk bekerja dengan baik, mengesampingkan masalah pribadi agar tidak berpengaruh terhadap kinerjanya di rumah sakit, dan membina hubungan yang baik terhadap rekan kerja baik itu sesama perawat, staf, dan atasan. Agar tercipta lingkungan yang nyaman ditempat kerja.

\section{KESIMPULAN}

Hasil penelitian ini menunjukkan dari 43 orang perawat di Ruang Rawat Inap Melati dan Seruni RSUD Dr. M. Yunus Bengkulu terdapat 21 orang perawat $(48,8 \%)$ mengalami stres kerja ringan, 19 orang $(44,2 \%)$ stres kerja sedang dan 3 orang lainnya $(7 \%)$ mengalami stres kerja berat. Terdapat 20 orang perawat $(46,5 \%)$ kinerja perawat baik, 22 orang $(51,2 \%)$ kinerja perawat cukup dan 1 orang $(2,3 \%)$ kinerja perawat kurang baik. Hasil penelitian ini menunjukan ada hubungan antara stress kerja dengan kinerja perawat di ruang rawat inap Melati dan Seruni RSUD Dr. M. Yunus Bengkulu.

\section{DAFTAR PUSTAKA}

Fajrillah\& Nurfitriani. (2016). Hubungan Stres Kerja Dengan Kinerja Perawat Dalam Melaksanakan Pelayanan Keperawatan Di Instalasi Gawat Darurat Rumah Sakit Umum Anutapura Paku. Jurnal Keperawatan Sriwijaya, volume 03-Nomor 02, 23555459

Gibson, James L. 1997. Organisasi, Perilaku, Struktur dan Proses. Edisi ke-5. Cetakan ke-3. Jakarta: Penerbit Erlangga.

Haryuni, S., Ratnawati, R,\& Kapti, E. R. (2013). Hubungan Antara Stres Kerja Dengan Kinerja Perawat di Instalasi Gawat Darurat RSUD Ngudi Waluyo Kabupaten Blitar dan RSUD Mardi Waluyo Kota Blitar. Jurnal Keperawatan, 56-52, 2086-3071

Luthans, Fred. 2011. Organizational Behavior : An Evidence-Based Approach. New York: McGraw-Hill.

Nainggolan, V. R. (2018). Hubungan Stres Kerja dengan Kinerja Perawat Pelaksana di RSUD Bina Kasih Medan Tahun 2017. Skripsi, Publikasi (2018), Universitas Sumatra Utara Medan.

Nasution, A, I, Z. (2009). Pengaruh Karakteristik Individu dan Psikologi Terhadap Kinerja Perawat dalam Kelengkapan Rekam Medis Di Ruang Rawat Inap Rumah Sakit Umum Dr. Pirngadi Medan. Tesis, 
Univesitas Sumatra Utara Medan.

Perwitasari, T. D., Nurbeti, N, \& Armyanti, I. (2016). FaktorFaktor yang Mempengaruhi Tingkat Stres Pada Tenaga Kesehatan di RS Universitas Pontianak Tahun 2015. Jurnal Cerebellum, vol 02.no 03

Rahman, A,. Salmawati, L, \& Suatama, P. I. (2017). Hubungan Stres Kerja Dengan Kinerja Perawat di Ruang Rawat Inap Rumah Sakit Bhayangkara Palu. Jurnal Kesehatan Tadulako, vol.03.no.02, 64-68

Sani, A. D. P. (2014). Hubungan Stres Kerja dengan Kinerja Perawat di Instalasi Rawat Inap Ruang Melati (C2) RSUD DR. M. Yunus Bengkulu. Skripsi , tidak diterbitkan, STIKES Tri Mandiri Sakti Bengkulu

Triwibowo, C. (2013). Manajemen Pelayanan Keperawatan. Jakarta: TIM

Wollah, O. M,. Rompas, S, \& Kallo, V. (2017). Hubungan Antara Stres Kerja Perawat Dengan Kinerja Perawat di Instalasi Gawat Darurat dan Intensivecare Unit RSU Pancaran Kasih GMIM Manado. e-journal Keperawatan, volume 05Nomor 02.

Wollah, O. M,. Rompas, S, \& Kallo, V. (2017) . Hubungan Antara Stres Kerja Perawat Dengan Kinerja Perawat di Instalasi Gawat Darurat dan Intensivecare Unit RSU Pancaran Kasih GMIM Manado. e-journal Keperawatan, volume $\quad 05$ Nomor 02 